\title{
Lo barrial del barrio. Una discusión desde el habitar subalterno en Bahía Blanca (Argentina)*
}

\author{
Neighborhoodness in the neighborhood. A discussion on subaltern living in Bahía Blanca, Argentina \\ José Ignacio Larreche \\ Universidad Nacional del Sur-CONICET, Argentina \\ joseilarreche@gmail.com
}

\section{Resumen:}

El presente escrito quiere conocer las experiencias del habitar de sujet@s autoidentificad@s gais y lesbianas en clave barrial. Los datos surgieron de conversaciones y entrevistas, y fueron complementados por la observación en el terreno, situados en la ciudad intermedia de Bahía Blanca, al sudoeste de la provincia de Buenos Aires. La perspectiva geográfica fue enriquecida por la semiótica y la antropología urbana asumiendo un abordaje cultural. A partir de la deconstrucción de los imperativos que cimientan lo barrial (familia, tranquilidad y pasado), se pueden explicar reajustes interbarriales en las trayectorias individuales, que dan como resultado la activación de determinadas áreas de la ciudad. Finalmente, esta apuesta se distancia de la ciudad como entidad totalizadora y, desde voces poco escuchadas, busca abrir la escala barrial para demostrar los condicionamientos que se intercalan en el tránsito de lo cotidiano.

Palabras ClaVE: Geografía ordinaria, Identificaciones gai-lésbicas, Escala barrial.

\begin{abstract}
:
This paper aims at delving into the neighborhood living experiences of self-identified gay and lesbian subjects. Data was gathered from conversations and interviews, and complemented by observation in the field, located in the intermediate city of Bahía Blanca, to the southwest of the Buenos Aires province. The geographical perspective was enriched by semiotics and urban anthropology, within a cultural approach. Inter-neighborhood readjustments in the individual trajectories that result in the activation of certain city areas can be explained from the deconstruction of the imperatives that found the notion of neighbourhood (family, tranquility and past). Finally, this view is distanced from the city as a totalizing entity and, from the perspective of barely heard voices, seeks to open the neighborhood scale to demonstrate the conditionings woven in the transit of everyday life.
\end{abstract}

KEYWORDS: Ordinary geography, Gay-lesbian identifications, Neighbourhood scale.

\section{INTRODUCCIÓN: DE LAS GEOGRAFÍAS HEGEMÓNICAS A LAS GEOGRAFÍAS ORDINARIAS}

La predisposición a indagar la cuestión espacial de sujetos subalternizados por su orientación sexual por parte de la geografía latinoamericana ha sido exótica, con excepción de Brasil. ${ }^{1}$ A diferencia de lo que acaece con la geografía del género (Lan, 2016), la geografía de las sexualidades es todavía un asunto con poca atención por parte de los afiliados a esta disciplina. En Argentina, dicho hiato ha sido subsanado por la aproximación liderada por otras ciencias sociales como la sociología, antropología, comunicación y la historia. $^{2}$

A juzgar por los orígenes institucionales de sus autores, los estudios existentes, con distintos encuadres témporoespaciales, se deprenden de las tres metrópolis más importantes del país: Ciudad Autónoma de Buenos Aires, Rosario y Córdoba. No se trata de equiparar estas ciudades simplemente por su peso demográfico, lo que resulta estéril para los entramados de la investigación social, pero sí de señalar una tendencia en los puntos de partida relativos a tópicos sociosexuales que van "más allá de la gran ciudad” (Langarita Adiego et al., 2019) y justifican nuestro caso. Estos escritos, pioneros en la problematización de las identificaciones sexuales y sus oscilantes prácticas, comparten dos tipos de vicios. El primero está vinculado a los sujetos de análisis: varones gais. Para estos trabajos, las subjetividades lesbianas 
parecen estar silenciadas (Figari y Gemetro, 2009) -Para hombre ya estoy yo: masculinidades y socialización lésbica en un bar del centro de Rio de Janeiro(otra metrópolis) es uno de los pocos trabajos etnográficos encarados por una autora argentina (Lacombe, 2006) -, y lo propio ocurre con las identidades trans. El segundo vicio se apoya en el área de estudio que se proyecta. Este último es un sesgo de tipo geográfico, que suscribe que generalmente la condición metropolitana es determinante en el devenir de ciertas biografías personales. Buenos Aires y sus alrededores ha sido el recorte del estudio sociológico de Meccia (2006); la ciudad de Rosario y las fiestas de osos de la capital cordobesa fueron los terrenos etnográficos de Sívori (2005) y de un grupo de investigadores de la Universidad Nacional de Córdoba (Liarte Tiloca y Recher, 2014), respectivamente.

El cúmulo de personas desdiferenciadas por la vorágine de "lo urbano" (Delgado, 1997) experimentada en el cotidiano corrompe la fijeza y la atención que puede depositarse sobre la individualidad, que se vuelve borrosa y pasa desapercibida. Este tipo de impacto puede referirse al conjunto de las minorías, entre ellas, las sexuales, y no siempre pensarse como un factor que resuelve una problemática más profunda, sino como una circunstancia interesante en procesos de subjetivación incipientes. Como sostiene Bech (1997), solo en las masas de extraños, los estilos, prácticas e identidades homosexuales modernas emergen. Este anonimato ha permitido que en momentos tanto de clandestinidad como de liberación se haya estimulado un coraje colectivo con distintos grados de efusividad, lo que posibilitó el ensamble de las primeras organizaciones y movimientos reivindicativos del Buenos Aires de los 80 . Una vez en lucha, estos grupos siguieron en otro tipo de anonimato bajo el patrón grupal (si antes parecían no estar o ser los otros, ahora se entenderán como una subpoblación homogénea), que derivará en nichos espaciales (Meccia, 2006) más ligados a un circuito de consumo expresado en boliches, saunas, zonas de yire, entre otros.

La decisión metodológica de la escala de análisis nunca está exenta de reproches. De hecho, esta no fue afrontada gratuitamente por Meccia, a pesar de expresar claramente su interés por las grandes ciudades. En el recorrido de su obra La cuestión gay reconoce la deuda latente en relación a itinerarios no metropolitanos:

Con tristeza, nos dimos cuenta enseguida que esta investigación que realizamos tomando solamente la Ciudad de Buenos Aires y sus alrededores podría hacerse en el interior, donde hay mucho sufrimiento acumulado en busca de una vía de escape... en busca de narración (2006, p. 65).

Asimismo, Sívori señala que los bares y clubes nocturnos para homosexuales en la postdictadura se convirtieron en los primeros y principales espacios urbanos en ser públicamente reconocidos como instituciones gais. A este circuito lo circunscribe a "Buenos Aires, Córdoba, Rosario y otras ciudades de menor porte” (2005, p. 33), sin detallar cuáles serían estas últimas. Otros autores han conjeturado sobre los encuentros y desencuentros propiciados por las tecnologías instantáneas y anómicas, como las aplicaciones de citas, que podrían llegar a ser significativas en las ciudades pequeñas (Boy, 2018; Miskolski, 2014), aunque tampoco se han aventurado en trabajos empíricos que pusieran en vigor dichas presunciones. Interesa, por todo lo expuesto, encauzar un nexo entre espacio y sociabilidades alojadas en localidades no metropolitanas, no capitalinas y no cosmopolitas, ${ }^{3}$ pero sin caer en la replicación de la dicotomía campo-ciudad.

El presente caso se anclará en la ciudad de Bahía Blanca, un nodo urbano de rango medio del sector sudoeste de la provincia de Buenos Aires con poco más de 300.000 habitantes según el último censo nacional. Se plantea como objetivo conocer las experiencias del habitar de sujet@s autoidentificad@s gais y lesbianas en clave barrial. Tomaremos el sentido del habitar que propone el arquitecto colombiano Yory basándose en Heidegger. El autor le imprime un carácter existencial al acto de habitar, que reúne inseparablemente ser y estar, y, por lo tanto, "en cada ahí que somos, como humanos (habitando) nos mostramos, precisamente, en lo que somos (habitantes)" (2015, p. 49).

Se entenderá a Bahía Blanca como una geografía ordinaria (Brown, 2008) en dos instancias. En primer lugar, el autor establece la necesidad de examinar cómo estas sexualidades se desarrollan en ciudades en donde no se ha colado tan fácilmente el capitalismo rosa que se gestó en las ciudades globales, en las que como saldo 
se siguió privilegiando la homonormatividad alimentada por intersecciones de clase, de género, e inclusive de etnia. Aquí se propaga un patrón asimilacionista de las pautas heteronormativas, en función de activar una cierta tolerancia social en oposición a la idea de disidencia. En ese sentido Taylor et al. (2010) alegan la importancia de considerar la localización como un criterio a incluir desde una interseccionalidad que no solo pondere dinámicas de clase, género, raza e identidad étnica, sino que abarque un cúmulo de otras influencias determinantes, como la nacionalidad, la fe, la geografía, la edad, la generación, la capacidad, la discapacidad y la sexualidad.

Al enlazar homonormatividad y geografía cultural se moldea la noción de metronormatividades (Halberstam, 2005; De Almeida Texeira, 2015) definida como un dispositivo que regula los desplazamientos hacia centros metropolitanos, cuya "atmósfera de libertad" permite una "salida del clóset" ${ }^{4}$ menos riesgosa. Cabe destacar que las metronormatividades suelen ser asociadas a contextos urbanos mayores, pero eso no las exime de posibles inscripciones en ciudades secundarias.

En segundo lugar, Brown sugiere la importancia de virar hacia la periferia de la periferia, es decir, exceder aquellos distritos, en términos de Lynch (1966), o sectores de una ciudad vinculados con la centralidad, función nucleadora o semiosfera, y enfatizar los procesos sociales de los suburbios: "no sólo el corazón de la ciudad, sus espacios de ocio y vecindarios gentrificados" (traducido de Brown, 2008, p. 1216). Como consecuencia, la inclinación hacia la escala barrial o microlocal en el presente artículo es la que se adoptará.

Finalmente, el trabajo consta de tres partes sin considerar las conclusiones. La primera se encarga de iluminar la complejidad del barrio a partir de sus principales referentes y derivas teóricas; en la segunda se presentan aspectos geohistóricos de los barrios, que surgieron del nudo empírico, y en la tercera parte se desarrollan los resultados obtenidos para abrir una discusión inacabada.

\section{LA ESCALA BARRIAL}

El trabajo con la escala de barrial no ha sido profuso en la tradición geográfica, incluida meramente como escenografía en los planos para recortar áreas de estudio pero con escasas transposiciones teóricas. El esfuerzo comn ha sido precisar sus límites en un juego de contornos y destacar la fuerza identitaria que los cohesiona, producto de sinergias sociales con base en orígenes comunes. En un interesante trabajo, Tapia (2013) ha resumido el tratamiento del barrio como una unidad autocontenida o como refugio de la comunidad y agregó que en los ltimos años ha sido también la escala más propicia para desplegar políticas o iniciativas de base local susceptibles de ser absorbidas rápidamente por los diseñadores de la planificación. Estos encuadres no se han detenido en lo que representa la condición barrial en los procesos contemporáneos de la ciudad (lvarez Pedrosian, 2018) que intentaremos exponer.

Cuando se piensa en el barrio como sinónimo de comunidad Ladizesky (2011) postula cuatro tipos de raíces en la patria del barrio: ${ }^{5}$ históricas, con base en la saga de familias que habitan el lugar; afectivas, en torno a amistades y parentesco; estéticas, que reposan sobre aspectos del paisaje, y étnicas, alusivas a grupos provenientes de otras regiones vecinas o lejanas, aunque estas poco nos dicen acerca de las repercusiones concretas que tienen estas culturas específicas sobre las particularidades vivenciales de personas no heterosexuales en el contexto actual.

Desde la semiótica, la sociabilidad debe ser entendida como parte de la dimensión "erótica" de la ciudad (Barthes, 1985). Esta acepción puede matizar distintas opciones de encuentro cuando nos referimos a estas identificaciones sociosexuales: en el espacio público, a través del ocio privado, mediante viajes, entre otros. Estos intercambios muchas veces se consuman en distintos puntos de la estructura urbana que se corresponden con barrios. Si se sigue este eje, el barrio suele ser pensado como aquello que es antónimo del centro (la semiosfera), y, de este modo, exalta singularidades que no se repiten o que no se espera encontrar en el centro y viceversa. Las narrativas de vida espaciales (Lindón, 2008) que trataremos darán cuenta de otros sentidos de los barrios, que no se reducen a la periferia. 
En muchas ocasiones los estudios barriales adoptan un interés socioeconómico, que determina áreas segregadas en tanto son habitadas por personas con insuficientes recursos para satisfacer sus necesidades básicas, en las antípodas de formatos de barrios cerrados, signados por la opulencia de sectores pudientes que eligen los suburbios como enlace de seguridad y diferenciación en los llamados procesos de gentrificación. En efecto, se presentarán casos que distan de este criterio del hábitat como parte de desencializar el barrio como villa ${ }^{6}$ o barrio popular, pero tampoco desplazarlo al formato de barrio country, desligándonos de apuestas que han visto al barrio como un área natural ${ }^{7}$ y acercándonos a una aproximación abierta del mismo: "abrir el barrio, tanto en tiempo como en el espacio; es decir, el barrio se construye y se modifica en relación al presente, el pasado y también al futuro, pero también en cuanto a la proyección de esta intersección de relaciones sociales a todas las escalas" (Tapia, 2013, p. 7). Por lo tanto, se sostendrá un abordaje cultural de los barrios, que los posiciona como subdivisiones formales y sociológicas con una personalidad particular (Vespucci, 2017). Estas subdivisiones, como las capas de una cebolla, contribuyen a comprender la ciudad en su conjunto cuando descendemos a lo molecular (Álvarez Pedrosian, 2018).

Gravano es un autor obligado para esta escala de indagación. El autor habla de lo barrial, en sustitución del barrio ${ }^{8}$ como un ethos que se consolida a partir de fórmulas nativas ${ }^{9}$ imbricadas en la asunción general de la territorialidad barrial: "muchacho de barrio", "le falta barrio", "no son de este barrio", "la chica de su casa es la del barrio" son algunas. Esta perspectiva está en sintonía con la dimensión simbólica barthesiana y se apoya en criterios vertebrales. El primero tiene que ver con el tiempo y más precisamente con el valor del antes como instancia experiencial más que cronológica. Es "la época base de la identidad barrial" (Gravano \& Guber 1991; Gravano 2013), en la que los fenómenos sociales se miden de forma nostálgica con respecto a un presente que se presenta sin rumbos promisorios. En esta dirección, el barrio es más un tiempo que un espacio, a pesar de que otros autores lo vinculan con el recuerdo adosado al ámbito rural (Muñoz, 1994).

En segundo lugar, lo barrial está construido a partir de elementos que se contagian, como los ideales que debe perseguir un barrio y que sus habitantes valoran. Entre estos, la tranquilidad aparece como un significante que se materializa en los ritmos lentos de su dinámica cotidiana. La vereda es el ámbito exclusivo del encuentro y reconocimiento del otro a través del saludo. A contrapelo, la calle, que contiene la vorágine del transeúnte, es un rasgo distintivo de la ciudad. Este supuesto hace de este último un espacio de flujos y del primero un espacio de lugares (Ladizesky, 2011). La tranquilidad se extiende a cualidades como la seguridad, la solidaridad entre vecinos y la decencia. Asimismo, la fisionomía del paisaje también indica qué tan cerca se está de la barrialidad; por ejemplo, las casas bajas, la plaza y el club son estandartes en este constructo, y lo no barrial se materializa en morfologías como departamentos y chalets. Vale señalar que el ethos es ético y estético, ya que impera "la celebración de la mismidad y el culto naturalizado de la endogamia" (Margulis et al., 2007).

Por último, el ímpetu del barrio requiere membresías que sean reguladas por un formato familiar nuclear: un padre, una madre y sus respectivos hijos. Las familias que viven en sintonía con lo barrial se enorgullecen de educar a sus hijos alineados con esquemas tradicionales, que llevan a reafirmar algunos ejes como el mencionado anteriormente, detrás del cual aparecen los mandatos de trabajar o estudiar, y la tranquilidad que esconde la disciplina de la conducta bajo las prerrogativas de no fumar o no retornar muy tarde al salir de noche. Gravano postula que el barrio es una "gran familia" que encapsula a los espacios domésticos de cada familia. Esta se asume legítima si quien ejerce el control es el padre, quien ejerce una coerción y "llega incluso a condicionar el tipo de relación social que en el barrio puede tener la mujer (esposa o hija) y lo que la mujer puede llegar a conocer del mismo barrio" (2013, p. 141). Esta aclaración pone de relieve la persistencia de roles de género encolumnados en las costumbres y las implicancias espaciales propias de una geografía cultural. Dichas particularidades han definido una dicotomía sexo-genérica funcional con claras discriminaciones materializadas en el espacio: padre-producción-espacio público vs. madre-reproducción-espacio privado. De acuerdo a esto, el uso espacio-temporal que se haga del entorno directo y del resto de la ciudad será diferencial de acuerdo al género. En Espacio públicos, género y diversidad: geografías para unas ciudades inclusivas, García 
Ramón y sus colaboradoras (2014) sostienen que el barrio se configura como una de las escalas sociales más interesantes para examinar el papel de las mujeres en la organización de su cotidianeidad y su sentido de pertenencia. ${ }^{10}$

Ante lo ilustrado, aquellos signos que atentan contra esta tipología se reducen a la "juventud de ahora" (Gravano, 2013), que contrapone una generación y un tiempo desde los que se encara la circulación social, ${ }^{11}$ asociados a una versión de peligro y amenaza para las costumbres tradicionales, la aparente paz y la institución familiar como fórmula perfecta. Anunciada la discusión, ante alegorías como "jóvenes eran los de antes", "peleas eran las de antes”, y, ¿por qué no?, "hombres eran los de antes”, cabe inferir la interrogación en torno al minúsculo pero decisivo plano de lo barrial: ¿qué efectos conllevará situar las socialidades gais y lésbicas en esta escala? ¿Qué repercusiones se avizoran cuando el "hijo del barrio" y la "mujer de su casa”, como invoca Gravano, buscan salirse de ese cinturón moral que los sujeta y presiona? ¿Serán permitidos armados domésticos homoparentales de acuerdo a lo barrial? Y, más aún, ¿cómo se sortea la influencia del vecindario a la hora de entablar citas, encuentros o demostraciones de afecto? Este debate es el que continúa en las páginas siguientes no sin antes presentar los fragmentos en cuestión.

\section{BARRIOS BAHIENSES ${ }^{12}$}

Previamente a señalar los casos empíricos, es preciso recalcar que estos se sitúan en la ciudad de Bahía Blanca, respecto de la cual no podemos determinar una desestructuración exigua de la vida moderna y con ella la desaparición del vecindario (Wirth, 1988; Park y Burgess, 1984), aunque sí se pueden filtrar esquemas que asocian al barrio como la última trinchera de valores de identidad, memoria y pertenencia (Tapia, 2013). En este aspecto, las referencias que surgieron durante las entrevistas (y luego fueron observadas) han sido el centro y tres barrios (Figura 1), de los cuales dos responden al ethos de lo barrial. Noroeste y Villa Mitre, y el restante, que es el barrio Universitario, junto a los que configuran el llamado "centro" (Microcentro I y II), actúan como los espacios posibles (Leroy, 2005) para un habitar subalterno. 
FIGURA 1

Barrios en foco.

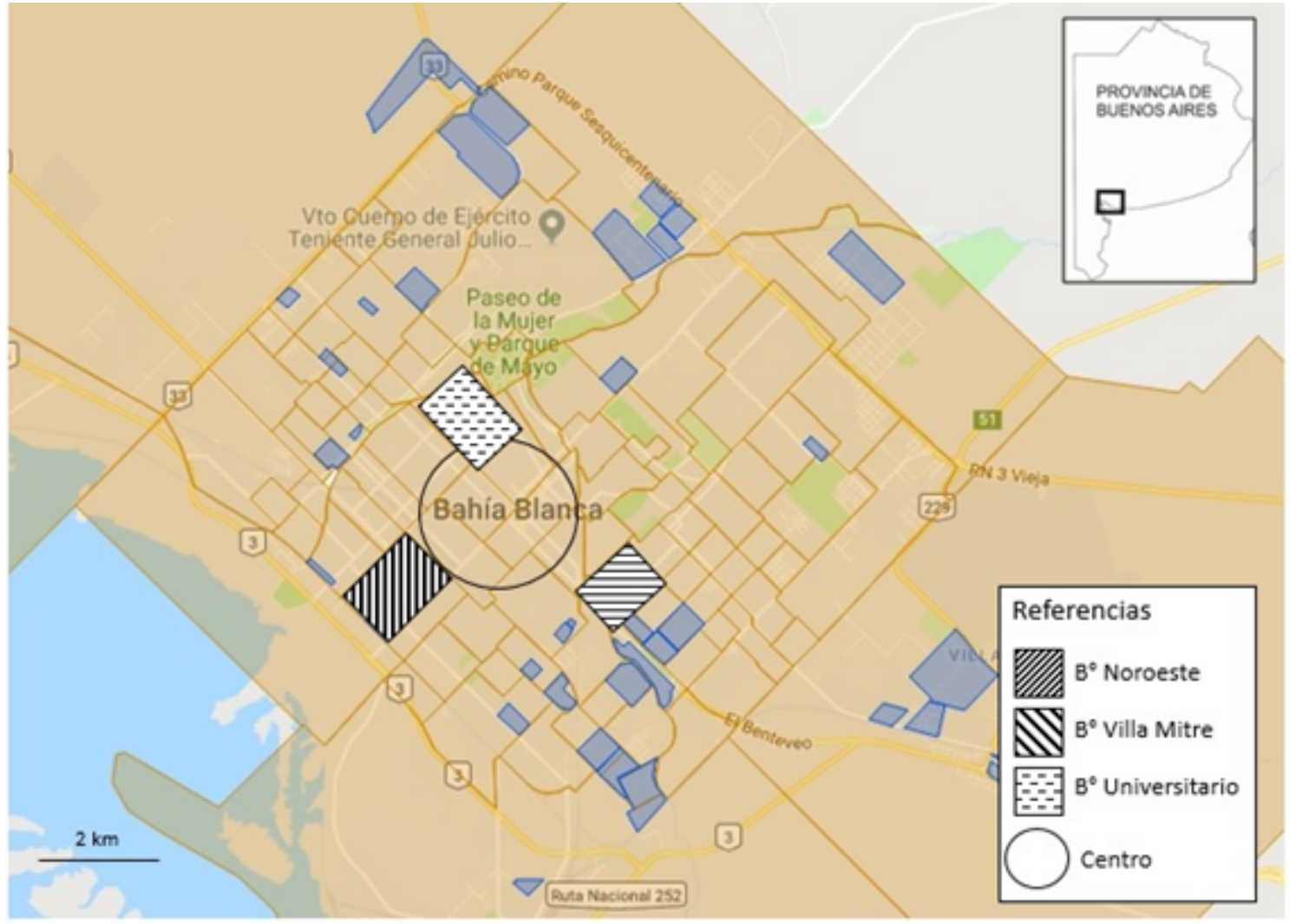

Fuente: Larreche, 2018.

El barrio Noroeste (llamado así a pesar de estar en el sudoeste de la ciudad) se gesta adosado a la línea férrea con dirección a La Pampa en 1887 y constituye el primer barrio de la ciudad. Los obreros inmigrantes sirios, polacos, rusos e ingleses contratados por la empresa ferroviaria fueron sus primeros pobladores. Como explican los chicos de la plaza Tambor de Tacuarí cercana: "nuestro barrio fue acuñado por una bella melodía: la que se desprende del trabajo. La de los golpes de martillo y mazas asegurando rieles y durmientes. Nuestro barrio es barrio de trabajadores"( La Nueva Provincia, 2004). Además de los talleres ferroviarios y dos importantes escuelas salesianas, este barrio concentra varios clubes deportivos, entre los que se destacan Velocidad y Resistencia, El Danubio, y Catamarca, donde la práctica de fútbol, básquet, bochas y karate queda reservada a los varones. Por otro lado, el barrio Villa Mitre fue fundado en 1906 a partir de un particular diseño, con cortadas y diagonales, producto de encontrarse contenido por los ejidos ferroviarios de las compañías inglesas y francesas del ferrocarril y el cauce del arroyo Napostá. Por esta razón desarrolló desde su creación un relativo aislamiento de la órbita central de la ciudad en paralelo a un reforzamiento del arraigo de sus habitantes (inmigrantes mayoritariamente sirio-libaneses), lo que sedimentó su identidad como barrio obrero (Conde et al., 2012). En sus inicios, su ocupación concentraba compadritos y malevos en el imaginario elitista de la Bahía Blanca, que traducía el paso por las vías como un acto peligroso (Sabanés, 2012). Esta presunción se modificó con el tiempo ante la irrupción de otras políticas, pero su protagonismo no mermó y compone, junto a sus aledaños Bella Vista y Tiro Federal, la "República de las Villas". En esta rápida radiografía, El Fortín, como se denomina a los integrantes de la hinchada del Club Villa Mitre, es una marca que irradia en forma mayúscula su territorialidad barrial.

El origen del barrio Universitario se vincula a la instalación de la Universidad Nacional del Sur en 1948 (en ese momento Instituto Tecnológico del Sur), por lo que gradualmente se constituyó en un espacio residencial con aires académicos ( La Nueva Provincia, 2004). En la actualidad, la senda de avenida Alem 
concentra varios puntos de confluencia para jóvenes y adultos procedentes de otros barrios de la ciudad. La oferta involucra cervecerías, cafés y restoranes, intercalados con edificios en altura y clubes deportivos (Club Liniers, Universitario y Napostá) que incluyen actividades de tipo mixta. Si bien no podemos diagnosticar fehacientemente que la función condiciona el sentido, creemos interesante reparar en el espacio material a partir de algunos usos del suelo para comprender la inmaterialidad que se exhibe en los deseos y representaciones de los usuarios de estos barrios, que ponen en diálogo ambas esferas de acuerdo a sus experiencias del habitar.

\section{ESPACIALIZANDO TESTIMONIOS, SORTEANDO BARRERAS}

Las entrevistas efectuadas para otros estudios de exploración ${ }^{13}$ despertaron el interés por la categoría barrio sin preverlo; las trayectorias valorativas al habitar los barrios o circundarlos afloraron una y otra vez por partede1@s protagonistas. En general se trató de sujet@s autodefinid@scomo gais y lesbianas en una proporción procuradamente pareja en género y edades. Las conversaciones fueron pautadas en un espacio elegido por ell@s, que podía ser de índole pblico o privado. A su vez, la condición civil y actividad laboral de 1@s mism@s sugiere establecer una distinción. Por un lado, una situación de dependencia del seno familiar principalmente en aquell@s menores de 30 años, y, por otro lado, una situación de emancipación para quienes superan ese parámetro. Este punto ayuda a explicar las dificultades de encuentro en una unidad privada para el primer grupo, y, por lo tanto, la importancia de procurar la exogamia para colmar sus expectativas, fomentando refuerzos en el espacio exterior, en tanto resulta más "accesible". Para el segundo grupo, el análisis está más ligado a las compatibilidades con el vecindario, ${ }^{14}$ pero, independientemente de esto, en ambos focos aparece la negociación de usos, las intermitencias de la ocupación y, en ltima instancia, la articulación de los barrios.

El denominador compartido que adquieren los itinerarios de socialización relatados en torno a barrios tradicionales es que discurren de forma rastrera y tensionada. Se puede ilustrar lo dicho con el caso de Lisandro (24 años) acerca del barrio Noroeste, su entorno inmediato, por donde simplemente divaga. Sus decisiones de encuentro con otros chicos aparecen condicionadas por el carácter simbólico que edifica el barrio: "es un barrio de familia, no se ve nada que tenga que ver con eso -en relación a un posible encuentro-; si te ven sentado en una plaza con alguien te pueden mirar raro, es muy incómodo". Cuando Lisandro alude a lo familiar del barrio está poniendo en cuestión la zona de contacto mutuo (Ladizesky, 2011) o la proximidad cerrada en el grupo primario (Tapia, 2013) de lo barrial, que hemos expuesto. En este sentido, el entrevistado sabe que requiere valentía consensuar un careo con otro par en la plaza de "su" barrio, pero también reconoce características de barrio envejecido y una fuerte represión ante la poca cantidad de perfiles que aparecen cuando consulta las redes virtuales. ${ }^{15}$ Las aplicaciones de cita no parecen incentivar una visibilidad en el territorio, ya que sigue rigiendo un comportamiento en penumbras asociado con el riesgo. "He visto pocos perfiles cerca, y de esos, ninguno muestra la cara", se lamenta. Las variantes que puede adoptar la entidad espacial como física/material o virtual/ficticia son aunadas por el mismo sentimiento coercitivo en sus manifestaciones microlocales. En el entorno material, el velo está puesto sobre las expresiones de género ${ }^{16}$ no heterocentradas del cuerpo, aunque el rostro parece ser el aspecto sensible en la experiencia virtual; en lo que se denomina perfil se plasman exclusivamente pectorales, genitales, caras sin rostros o paisajes naturales.

Como parte de otro registro, Daniel (23 años) sabe que tiene vecinos gais y cuando, "luego de pensarlo mucho", acordó un día de encuentro con uno de ellos (previamente chatearon por la aplicación de citas mencionada), nos comenta que prefirió desplazarse al centro para consumar su cita; "cerca del barrio me siento observado" fundamenta. Este último entrevistado vive en Villa Mitre, barrio al que describe de la siguiente manera: 
es un barrio futbolero, los chicos juegan al fútbol en la plaza y los domingos van a ver al club a la cancha (...) cuando voy solo, eso me pone un poco nervioso más que nada porque van en grupo (...) imagínate si estoy acompañado de un puti (Daniel, registro de entrevista).

En esta dirección, el encubrimiento (Goffman, 1970) que practica Daniel en su habitar está en estrecha relación con una subcultura misógina y homolesbofóbica, que exacerba el fútbol y que puede exponerlo a la agresión verbal y física. Por eso, además de los cánones citados, el fútbol o, mejor dicho, "el potrero" se afincan como otro baluarte de lo barrial. Marcelo Urresti ${ }^{17}$ estudió algunos sectores populares de la ciudad autónoma de Buenos Aires y acuñó la expresión "cultura del aguante" ${ }^{18}$ en torno a una subcultura de la cancha y la tribuna. De este análisis, delinea que es importante "la defensa territorial de los colores y la división del terreno propio o ajeno" (2007, p. 283), en coherencia con un tipo de solidaridad grupal que ejercen los hombres llamada homosociabilidad o hermandad. La impronta futbolística permea al barrio Villa Mitre en la cromática de sus colores (verde, blanco y negro), visible en numerosos paredones, postes de luz y garajes particulares (Figura 2). El paisaje provisto ejerce una dimensión comunicacional (Álvarez Pedrosian, 2018) de una serie de elementos entendidos como lo típica y fenotípicamente barrial.

FIGURA 2

Mural dedicado a "La Gloriosa” (Club Villa Mitre).

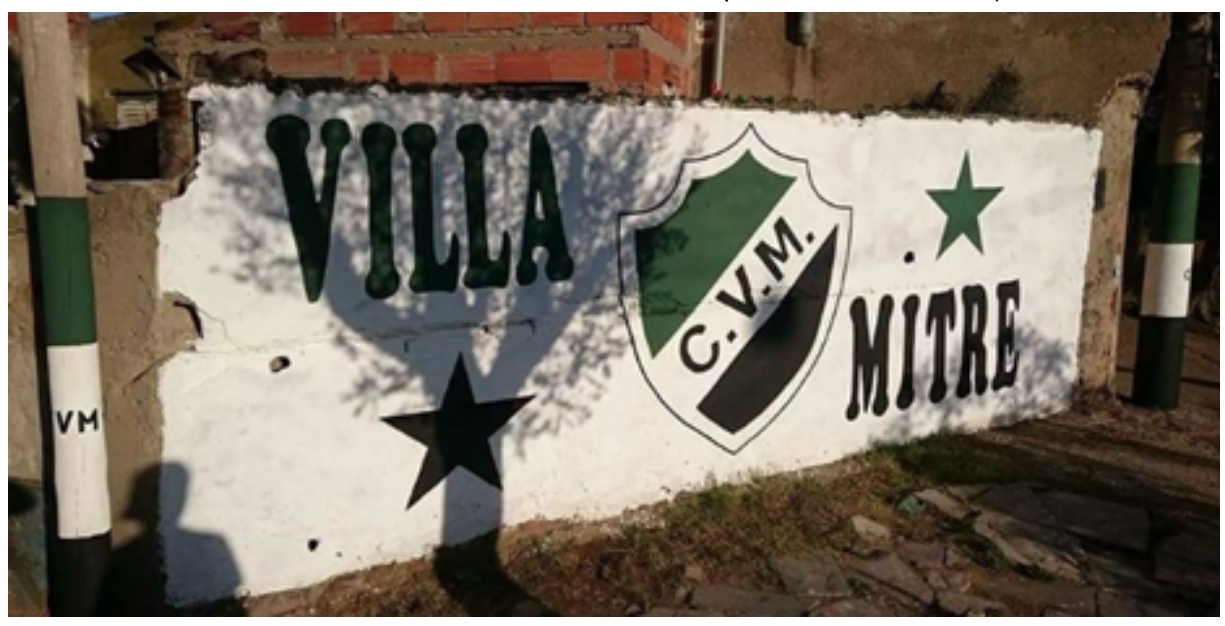

Fuente: barrabrava.net, 2018 .

Ante lo expuesto y en vista de nuevas citas, Daniel expresa su preferencia por segmentos del centro alternados entre la plaza central o locales de licuados y comidas rápidas. En la búsqueda de registros espaciales, la fuga del control familiar-vecinal es clave para el entrevistado al igual que para Lisandro. El peso que persiste sobre el prototipo familiar y el vecindario, con su efecto multiplicador de "gran familia" -causado por la alta frecuencia de coincidencias interpersonales que dan lugar a los comentarios-, son factores elocuentes. En esta misma dirección, Natalia (30 años) se percata que la primera vez que escuchó acerca de otra lesbiana fue cuando "el barrio hablaba" específicamente de una vecina cuyo cuerpo "subvertía el género", ya que denotaba un trabajo de gimnasio sorpresivo para el verdulero que la atendía.

Los barrios que surgieron con el ferrocarril, como Noroeste y Villa Mitre, parecen responder al panóptico que describió Foucault en el devenir del habitar subalterno. En este control, el atributo futbolero obliga una nueva indagación. Muchas veces, la apropiación del espacio barrial -es decir, la territorialidad barrial (Álvarez Pedrosian, 2018) -, es medida en función de este deporte popular para la población argentina. Urresti \&y Cecconi (2011) señalan un ejemplo orientado a ello: "jugar en mi barrio es más lindo que hacerlo en la Bombonera"; esto comenta Carlos Tévez, un reconocido futbolista profesional, en relación a su Fuerte Apache natal, ubicado en la provincia de Buenos Aires. La puntualización que realiza el exponente, en este caso sobre una villa, desnuda las dos caras de esta escala: el orgullo y la filiación; un antes latente en tanto 
nostalgia de lo que fue pero con continuidad en el presente. En la intención de presentarse como bahiense o como vecino de Villa Mitre se explicitan credenciales geográficas, que son estratégicas de acuerdo a cuál sea el objetivo y la audiencia receptora, y que indudablemente jerarquizan un tipo de patriotismo microlocal. El ethos barrial anclado en el fútbol opone obstáculos en los despliegues públicos de 1@s informantes, particularmente esto sucede con los varones gais. Daniel repasa que cuando hay partido prefiere no salir y sabe que estar en la plaza con otro chico puede ser peligroso porque los hinchas "andan en manada". El barrio es el ámbito del encuentro repetido (Ladizesky, 2011) con los parientes, los vecinos, pero también es el lugar donde se monta una escenografía con los aficionados que pivotean el lugar durante el día y la noche, e inauguran discrepancias topofílicas en un espacio que parece unívoco (Larreche y Nieto, 2017). Cabe destacar que la hinchada de Villa Mitre ejerce una vigilancia territorial que puede no representar inquisiciones para los habitantes del barrio en general, pero sí para estas minorías sexuales en particular. Asimismo, el club como condensador de sociabilidades en Villa Mitre y Noroeste no ofrece demasiadas alternativas a quienes no practiquen fútbol, y si son chicas las que quieren hacerlo (hasta el momento de elaboración de este artículo), no existe un nicho para ellas. ${ }^{19}$

La historia de Jorge y su esposo en relación a Villa Mitre brinda otros aportes. El informante expresó que ninguno de sus vecinos los saludaba cuando recién se habían mudado y reflexiona que "cierta extrañeza se produce al ver a dos personas del mismo sexo conviviendo en un barrio tipo de clase media”. Esta referencia otorga énfasis a la funcionalidad mercantil que se introdujo con la noción de metronormatividades en la ciudad. La clase y la localización parecen predestinar al concubinato gai a tipologías de barrio menos tradicionales y más exclusivas. En este sentido, son abundantes los trabajos a partir de los llamados distritos gay de París, Madrid, San Francisco, e inclusive se podría extender a las atmósferas barriales de Recoleta y Palermo de la Ciudad Autónoma de Buenos Aires, que alimentan un imaginario de homonormatividad contundente. Esto es contrarrestado por las experiencias del habitar que tienen los mism@s sujet@s en los barrios del Conurbano. ${ }^{20}$ La destreza de la identidad discreta (Pecheny, 2002) sigue actuando como patrón ordenador en los barrios que auspician lo barrial. El caso que se difundió de Sofía del Valle, atacada por vecinos de Almagro cuando salía del subte y se dirigía a su trabajo, es esclarecedor. Sofía expresó que le gritaban "no queremos raritos en el barrio" ${ }^{21}$ y esto debe exigir un replanteo de qué tan próxima es la escala barrial más allá de su radio de influencia medido en distancia.

Que el problema para este habitar sea lo barrial y no el barrio queda claro con los comentarios de Gabriela (28 años), quien vivió en el barrio Universitario durante sus estudios en la ciudad. La entrevistada explica que en esos años "iba a vóley al Club Universitario y conocí muchas chicas lesbianas". El barrio también es mencionado por Lisandro, quien asegura: "aquí se llena de perfiles en Grindr", a lo que se suma la publicidad de actos afectivos observados en parejas yendo de la mano por la calle o besándose (principalmente chicas) mientras comparten una tarde de mates en algún espacio verde. En el barrio Universitario domina la juventud, un elemento que interpela lo barrial, porque allí reside gran parte de la población estudiantil que cursa sus carreras en la Universidad Nacional del Sur. ${ }^{22}$ No obstante esto, también se despliega una fisionomía que atenta contra la estética de lo barrial, en tanto las casas bajas coexisten con edificaciones verticales de pocos pisos, ${ }^{23}$ dispuestas como residencias estudiantiles. La influencia de la universidad propone una multiplicidad de usos del espacio que se estructuran a lo largo de la avenida Alem; se pueden apreciar cervecerías, bares y el famoso boliche El Club. ${ }^{24}$ Este conjunto rompe con la monotonía paisajística y altera la tranquilidad que es semblante en los otros. De hecho, Federico (32 años) reconoce esta personalidad de Universitario: "acá hay otra onda, se ven siempre pibes jóvenes, se oye música, hay vida y está minado de gais". A pocos metros en el barrio Pacífico, Verónica (48 años) comenta: "mi experiencia es muy buena, es más, no sé si la que alquila al lado es una familia vinculada al evangelismo que es muy buena onda conmigo y con mi compañera". Asimismo, el trabajo etnográfico también dejó al descubierto la presencia de una iniciativa conducente a visibilizar la alteridad sexual local. Se trata de un mural artístico en la intersección 
de las calle Nicaragua y Perú dedicado a la referente trans local María Eva Rossi (Figura 3), intervenido por la organización Orgullo Disidente con los colores de la bandera LGBT, y con una inscripción que busca provocar la atención de quien pase por allí: "Transformadora".

FIGURA 3

Mural dedicado a María Eva Rossi.

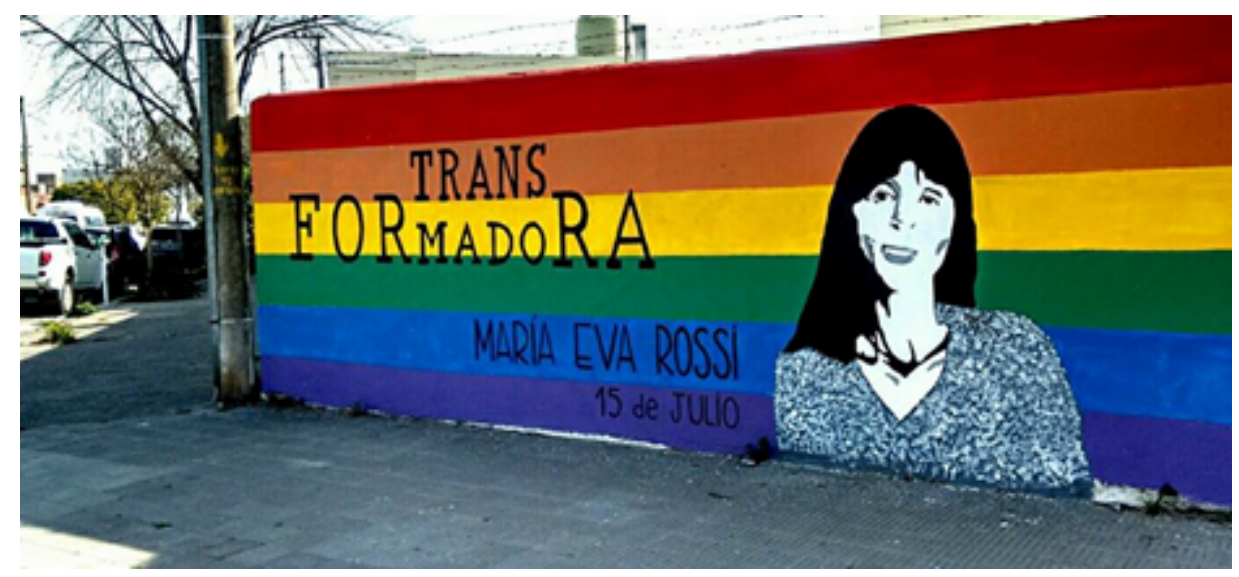

Fuente: Larreche, 2017.

En lo relativo a la ciudad nocturna, el relato de Luciano (28 años) relativiza el papel de algunas plazas barriales, cuando se metamorfosean en la desierta noche que caracteriza a lo barrial, por lo menos en otoño e invierno, y allí se puede apreciar un establecimiento nómade de los sujetos en cuestión: "me juntaba en la plaza porque no andaba nadie”; "íbamos en el auto con mi novio y tomábamos unos mates alrededor de la plaza". Por ende, el dinamismo nocturno privado del centro o de la zona de bares del barrio Universitario, concentrada en Avenida Alem y otros espacios satelitales al mismo (Paseo de las Esculturas, espacios de consumo sobre Fuerte Argentino), son compensados por una periferia pública resignificada por su apariencia libre de observaciones. De este modo, algunas plazas barriales se convierten en superficies de placer disponibles en el marco de "territorios ansiógenos" (Raibaud, 2007) regulados por la adrenalina de ser vistos. Esto no le sucede a Brenda (28 años), quien sentencia rotundamente, con la expresión "en la noche no podemos andar nosotras", que existen asimetrías con sus pares varones aun cuando se trate de prácticas furtivas. Como sostiene Soto Villagrán (2014), el orden urbano implica opresión y vulnerabilidad estructural en los espacios vividos de las mujeres, lo que aumenta sensiblemente en el espacio-tiempo de la noche de nuestras informantes, quienes sufren una doble marginación en los espacios abiertos por ser mujeres y lesbianas.

La mayoría de1@s entrevistad@s ha pautado interacciones sociales en escenarios del centro y próximos al barrio Universitario, que recrean otros climas culturales y morales. Estos segmentos apuntalan una plasticidad más próxima a lo urbano que a la rigidez de lo comunal ${ }^{25}$ expresada en los testimonios espacializados de Villa Mitre y Noroeste. Pensamos que la alta densidad juvenil puede ser un factor interesante, porque los jóvenes son los agentes espontáneos del cambio en la medida en que "socializan a mitad de camino entre las herencias de las generaciones previas y las innovaciones" (Urresti, 2007, p. 281), sin por eso cristalizar una apertura social inexorable en cada fragmento de la ciudad. Desafortunadamente el control de lo barrial ha significado para muchos varones jóvenes la replicación de ciertos mandatos heteropatriarcales, por ejemplo, cuando Natalia (30 años) menciona la amenaza de violación correctiva -por ser lesbiana- que sufrió por parte de sus vecinos en el barrio Villa Rosas.

Los barrios facilitadores por los que optan est@s sujet@s son activados durante el día en sectores con "menos" marca de lo barrial. Las estructuraciones de estos espacios por parte de subjetividades subalternas distan del significado que realza el centro para desplegar socializaciones signadas por la flexibilidad. Barthes 
propone encuadrarla como un "espacio lúdico" que favorece la alteridad; aquello que no es centro, es monotonía, es repliegue y no da lugar al otro (familia, residencia, identidad). Las opciones que surgen en el centro van desde intercambios sociales más pasivos (miradas) o más activos (comunicación, encuentro, tacto), pero también es la vitalidad de dicho territorio, dada por la sensación de seguridad por la continua y diversa presencia de personas, la que facilita la experiencia del habitar.Por esto mismo, 1@sconsultad@s eligen plazas, cafés y otros espacios tanto públicos como semipúblicos, que no solo componen sino que definen el carácter semiótico del centro, concebido como barrios de posibilidad más que de proximidad.

FIGURA 4

Trayectorias interbarriales.

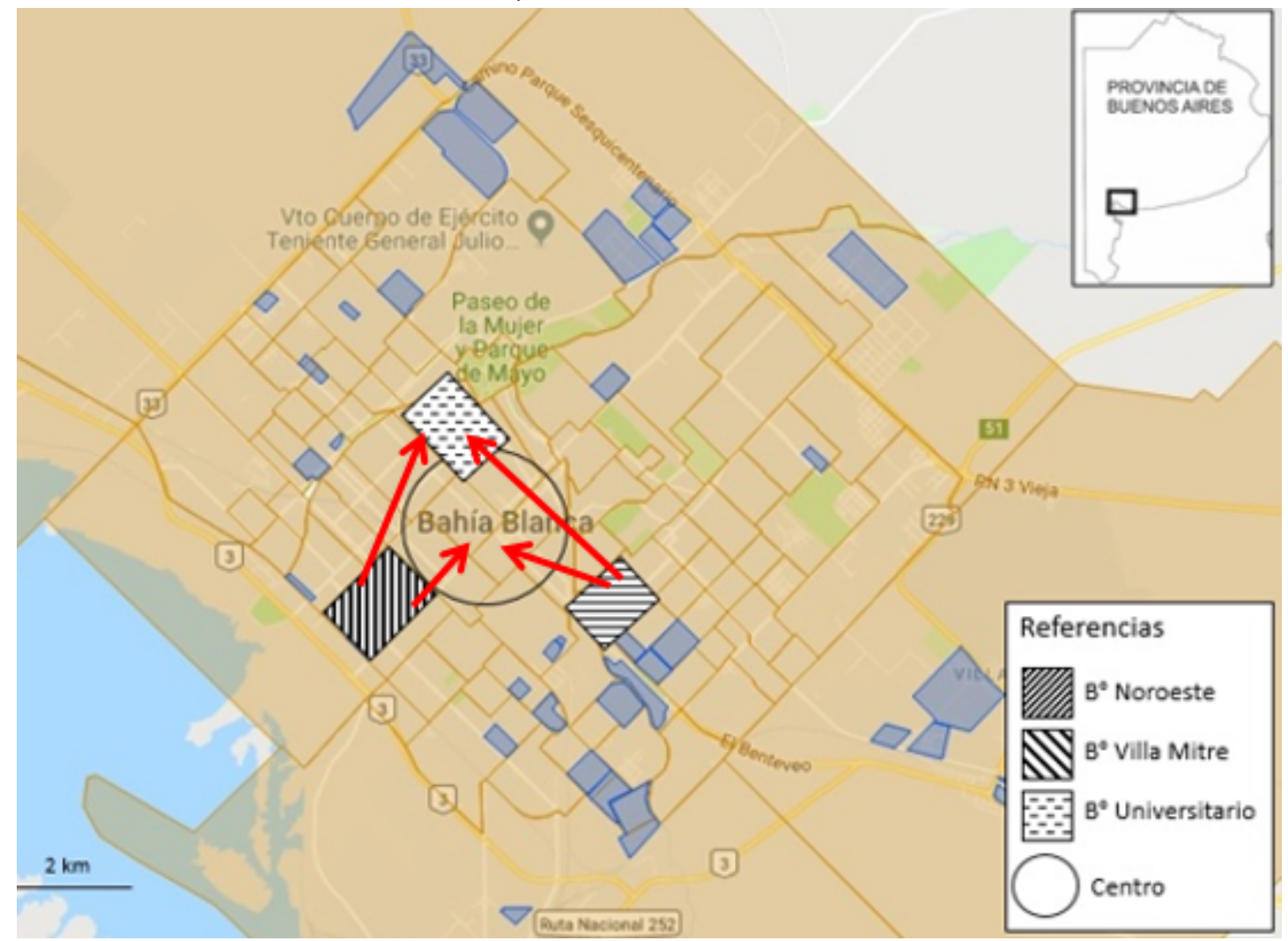

Fuente: Larreche, 2019.

\section{ConcLuSIONES}

Las páginas tendidas vehiculizaron una apuesta crítica de los procesos sociales enmarcados en la escala barrial desde una perspectiva que conjugó identificaciones sociosexuales no heterocentradas con el habitar. El barrio conforma solo una escala de análisis pero "lo barrial" es un espíritu social de gran impacto en los mecanismos de subjetivación subalternos. Usualmente, los barrios han sido imaginados y estudiados en clave de identidad vigorosa (popular, obrera) construida en retroalimentación con el poder de la tradición que termina por reportar exclusiones silenciosas para algun@s de quienes los residen, ocupan, recorren. En este sentido, est@sujet@s reactivan la dicotomía centro-periferia en una faz semiológica cuando exponen anécdotas, intenciones e interacciones fuera de sus barrios de origen, desacreditando la proximidad como posibilidad del habitar.

Villa Mitre y Noroeste comparten varios de los atributos que los posicionan como adeptos de lo barrial: son tranquilos, de conjuntos habitacionales homogéneos y acuñados en una órbita de conocimiento común por parte de sus vecinos. A esto se le suma la función que el fútbol y el club poseen como insignia en la 
comprensión de su dinámica. Este esquema remite repliegues y planificación para estas disposiciones de habitar subalterno, ya que en el barrio se desencadena una lógica de lo "peridoméstico", con pocas diferencias percibidas entre la casa y el barrio de pertenencia.

La juventud, las caras nuevas y los ritmos más acelerados del barrio Universitario y del centro exhortan a1@s sujet@simplicad@s a desplazarse hacia los mismos, en trayectorias que coronan determinados segmentos con nula articulación entre los portadores de lo barrial. Es decir, el habitar subalterno confluye en lo no barrial quitando potenciales articulaciones entre barrios aledaños. La noción de barrera geográfica (Maffia, 2016) puede también tornarse funcional cuando profundizamos el alcance de la relación entre barrios. Más cerca del espacio doméstico que del espacio "público", más ansiógeno que libertario, más zigzagueante que sedentario, el barrio sigue implicando, muchas veces, un espacio social aprehendido, que es dinámico en sus límites pero estático en vivencias alternativas. En esta dirección, hemos dado cuenta de las empatías urbanas (Agudelo Castañeda, 2015) manifestadas entre el quehacer erótico y distintas subculturas barriales.

En definitiva, este intentó ser un aporte para revelar que la geografía debiera colarse en estos debates, en tanto vuelca su visión a un diálogo interdisciplinar e interescalar sustantivo para abordar problemáticas contemporáneas.

\section{Agradecimientos}

A las Dras. Patricia Ercolani, Graciela Hernández y Laura Torres por su concienzuda lectura y valiosos aportes; a quienes evaluaron la versión inicial de este trabajo.

\section{Referencias bibliográficas}

Agudelo Castañeda, J. H. (2015). Del imaginario estético al imaginario social urbano. En los procesos de consolidación de empatías urbanas. Academia XXII, 7(13), 111-125.

Álvarez Pedrosian, E. (2018). Las territorialidades barriales y sus espacios de creación. En XIV Congreso de la Asociación Latinoamericana de Investigadores de la Comunicación.

Barthes, R. (1985). La aventura semiológica. Barcelona: Paidós.

Bech, H. (1997). When men meet: homosexuality and modernity. Cambridge: Polity Press.

Boy, M. (2018). El otro espacio público en los estudios urbanos de la Argentina actual: el género y las sexualidades también construyen ciudad. Quid 16. Revista del Area de Estudios Urbanos, 9, 153-167.

Braudel, F. (1968). La Historia y las Ciencias Sociales. Madrid: Alianza.

Brown, G. (2008). Urban (homo) sexualities: Ordinary cities and ordinary sexualities. Geography compass, 2(4), 1215-1231.

Conde, A., Cantamutto, L., Ortiz, M., y Díaz, M. (2012). De las vías para acá: cinco acercamientos a la historia de Las Villas. Bahía Blanca: Ediciones Macedoña.

De Almeida Teixeira, M. A. (2015). "Metronormatividades" nativas: migrações homossexuais e espaços urbanos no Brasil. Askesis, 4(1), 23.

Delgado Ruiz, M. (1997). Ciudad líquida, ciudad interrumpida. Medellín: Universidad Nacional de Colombia. Biblioteca Pública Piloto de Medellín.

Delgado Ruiz, M. (2007). Sociedades movedizas: pasos hacia una antropología de las calles. EURE, 33(98).

Figari, C., y Gemetro, F. (2009). Escritas en silencio. Mujeres que deseaban a otras mujeres en la Argentina del Siglo XX. Revista Latinoamericana Sexualidad, Saludy Sociedad, 3, 33-53.

García Ramón, M. D., Ortiz Guitart, A., y Prats Ferret, M. (2014). Espacios públicos, género y diversidad: geografias para unas ciudades inclusivas. Barcelona: Icaria. 
Goffman, E. (1970). Estigma: la identidad deteriorada. Buenos Aires: Amorrortu.

Gravano, A., y Guber, R. (1991). Barrio sí, villa también. Buenos Aires: Centro Editor.

Gravano, A. (2013). Antropología de lo urbano. LOM Ediciones.

Halberstam, J. (2005). In a queer time and place: transgender bodies, subcultural lives. Nueva York: New York University Press.

La Nueva Provincia (2004). Barrios Bahienses. Bahía Blanca.

Lacombe, A. (2006). Para hombre ya estoy yo: masculinidades y socialización lésbica en un bar del centro de Río de Janeiro. Buenos Aires: Antropofagia.

Ladizesky, J. (2011). El espacio barrial: criterios de diseño para un espacio público habitado. Buenos Aires: Bisman.

Lan, D. (2016). Los estudios de género en la geografía argentina. En M. V. Ibarra García e I. Escamilla Herrera (coord.), Geografias feministas de diversas latitudes: origenes, desarrollo y temáticas contemporáneas (pp. 55-70). México: Instituto de Geografía, UNAM.

Langarita Adiego, J. A, Mas Grau, J. M., y Jubany, O. (2019). Geografías de la diversidad sexogenérica más allá de la gran ciudad: experiencias, discursos y prácticas en dos ciudades medianas de Cataluña. Documents d'Anàlisi Geogräfica, 1-20.

Larreche, J. I., y Nieto, M. B. (2017). Discrepancias topofílicas en un espacio unívoco de Bahía Blanca. Estudio comparativo en torno a espacios escolares desde una mirada geográfica emergente. Revista Universitaria de Geografia, 26(1), 31-55.

Larreche, J. I. (2018). Las sexualidades y su capital espacial. Exploraciones teórico-situadas en la ciudad intermedia de Bahía Blanca, Argentina. Cuaderno Urbano, 25(25), 163-183.

Leroy, S. (2005). Le Paris gay. Éléments pour une géographie de l'homosexualité. Annales de Géographie, 646, 579-601.

Liarte Tiloca, A., y Recher, A. (2014). Cartografias del deseo. Espacios urbanos de (homo) sociabilidad en Córdoba. XI Congreso Argentino de Antropología Social. Rosario, Argentina.

Lindón, A. (2008). De las geografías constructivistas a las narrativas de vida espaciales como metodologías geográficas cualitativas. Revista da ANPEGE, 4(4), 7-26

Lynch, K. (1966). La imagen de la ciudad. Buenos Aires: Infinito.

Maffia, D. (2016). Barreras en el ejercicio de los Derechos Humanos. Poder Judicial de la Ciudad de Buenos Aires.

Margulis, M., Urresti, M., y Lewin, H. (2007). Familia, hábitat y sexualidad en Buenos Aires. Investigaciones desde la dimensión cultural. Buenos Aires: Biblos.

Meccia, E. (2006). La cuestión gay: un enfoque sociológico. Argentina: Gran Aldea Editores.

Miskolski, R. (2014). Negociando visibilidades: segredo e desejo em relações homoeróticas masculinas criadas por mídias digitais. Revista Bagoas, 11, 52-78.

Muñoz, S. (1994). Barrio e identidad: comunicación cotidiana entre las mujeres de un barrio popular. México: Trillas.

Park, R. \& Burgess, E. (1984). The city. Suggestions for investigation of human behavior in the urban environment. Chicago: University of Chicago Press.

Pecheny, M. (2002). Identidades discretas. En L. Arfuch (Comp.), Identidades, sujetos y subjetividades: narrativas de la diferencia (pp. 5-17). Buenos Aires: Prometeo.

Quinn, S. (2010). Guia del activista para usar los Principios de Yogyakarta. Recuperado de http://ypinaction.org/wpcontent/uploads/2016/10/Guia_del_activista_nov_14_2010.pdf.

Raibaud, Y. (2007). Le genre et le sexe comme objets géographiques. Sexe de l'espace, sexe dans l'espace, 2, 97-105.

Sabanés, E. (2012). Las palabras y las casas, los orígenes del barrio obrero. En A. Conde (Comp.), De las vías para acá: cinco acercamientos a la historia de Las Villas (pp.25-36). Bahía Blanca: Ediciones Macedoña,.

Scharagrodsky, P. (2004). Juntos pero no revueltos: la educación física mixta en clave de género. Cadernos de Pesquisa, 34(121), 59-76.

Soto Villagrán, P. (2014). Patriarcado y orden urbano. Nuevas y viejas formas de dominación de género en la ciudad. Revista venezolana de estudios de la mujer, 19(42), 199-214. 
Sívori, H. F. (2005). Locas, chongos y gais: sociabilidad homosexual masculina durante la década de 1990. Argentina: Antropofagia.

Tapia, V. (2013). El concepto de barrio y el problema de su delimitación: aportes de una apoximación cualitativa y etnográfica. Bifurcaciones, 12, 1-12.

Taylor, Y., Hines, R. \& Casey, M. (2010). Theorizing interseccionality and sexuality. Londres: Palgrave.

Urresti, M. (2007). De la cultura del "aguante" a la cultura del "reviente": cambios en la significación de la corporalidad en adolescentes y jóvenes de sectores populares. En M. Margulis, M. Urresti y H. Lewin, Familia, hábitat y sexualidad en Buenos Aires. Investigaciones desde la dimensión cultural (pp.281-292). Buenos Aires: Biblos.

Urresti, M., y Cecconi, S. (2007). Territorios subalternos: una aproximación a los sectores populares urbanos. En M. Margulis, M. Urresti y H. Lewin, Familia, hábitaty sexualidad en Buenos Aires. Investigaciones desde la dimensión cultural (pp. 39-59). Buenos Aires: Biblos.

Vespucci, G. (2017). Homosexualidad, familia y reivindicaciones. De la liberación sexual al matrimonio igualitario. Buenos Aires: UNSAM Edita.

Weeks, J. (2012). Lenguajes de la sexualidad. Buenos Aires: Nueva Visión.

Wirth, L. (1988). El urbanismo como modo de vida. En M. Bassols, R. Donoso, A. Massolo y A. Méndez [comp.], Antología de sociología urbana (pp. 162-182). México: Universidad Nacional Autónoma de México.

Yory, C. (2015). La construcción social del Hábitat: como estrategia de integración social, sustentabilidad urbana y seguridad ciudadana. Bogotá: Universidad Piloto de Colombia.

\section{Notas}

* Parte de lo volcado fue presentado en las Jornadas Platenses de Geografía y XX Jornadas de Investigación y de Enseñanza en Geografía celebradas en octubre de 2018 y enriquecido por las discusiones producidas en el IV Coloquio Internacional de Saberes Contemporáneos desde la diversidad sexual en la ciudad de Rosario en junio de este año. Por otro lado, se advierte que se empleará el “@” como arreglo inclusivo cuando se haga referencia a l@s informantes ya que se trata de identidades cis.

1 El Grupo de Estudios Territoriales (GETE) de la Universidad Estatal de Ponta Grossa publica semestralmente la Revista Latino-americana Geografía e Género que reúne desde el 2010 varios artículos con este enfoque.

2 Para una revisión de estos aportes ver Boy (2018), El otro espacio público en los estudios urbanos de la Argentina actual: el género y las sexualidades también construyen ciudad.

3 En su glosario sobre estudios de sexualidad, Jeffrey Weeks postula al cosmopolitismo como un concepto gestado en la globalización que "se basa en la creencia de que, a pesar de la multiplicidad de posibles lealtades políticas, los grupos humanos participan de la humanidad con una potencial serie compartida de valores y que personas distintas pueden encontrar un respeto mutuo y maneras de trabajar juntas a pesar la gran cantidad de diferencias que tienen entre si”" (2012, p. 61).

4 Expresión que refiere al proceso de autoaceptación y posterior comunicación sobre la identificación sexual sentida a un círculo de personas relativamente cercano.

5 Esta idea es acordada por Margulis bajo la noción de patriotismo local.

6 Cfr. Guber, 2013.

7 Los representantes de la visión ecologista de la Escuela de Chicago han justificado la inevitable existencia de los guetos bajo esta premisa.

8 Sus apuntes están basados en trabajos estructurados en torno a tres barrios de características similares, poblados por clase obrera industrial y pequeña burguesía comercial de extracción inmigratoria europea y provinciana en sus orígenes: Villa Lugano, Parque Patricios y Gerli.

9 Clifford Geertz establece la diferencia entre categorías nativas o próximas y las lejanas según el grado de vínculo con la experiencia.

10 Ana Falú y su equipo son otras investigadoras argentinas que se han dedicado a desdeñar la planificación androcéntrica y patriarcal de las ciudades del sur global.

11 Se elige esta idea y no la de cambio social siguiendo la clasificación de tiempos históricos de Braudel (1968), que, a grandes rasgos, divide como cortos (acontecimiento), medios (coyuntura) y largos (estructura) adscribiendo el cambio cultural al último grupo y por lo tanto resaltando su lentitud en el trastocamiento de esquemas interpretativos. 
12 El apartado fue elaborado con gran apoyo de la serie de fascículos "Barrios Bahienses", editados por el diario local $L a$ Nueva Provincia en el año 2004.

13 Ver Larreche, 2018.

14 Desde el censo de 2010 en Argentina son relevados los hogares homoparentales. Las causas de este avance se encuentran en la conquista del matrimonio igualitario (Ley 26.618) aprobada el 15 de julio de 2010.

15 La aplicación Grindr, citada por el entrevistado, permite divisar la distancia en metros que lo separan de otros usuarios, al asociar la cuenta con las coordenadas geográficas de Google maps.

16 Los "Principios de Yogyakarta" elaborados en 2007 en el marco de la Organización de las Naciones Unidas (ONU) conciben que las expresiones de género incluyen vestimenta, modo de hablar y modales, y es distinto del concepto de identidad de género (Quinn, 2010).

17 En su escrito también desanda la estrecha relación que existe entre el fútbol y el rock, condensado como "rock barrial", al que muchos barrios del conurbano inscriben, principalmente a partir de los años 90.

18 Asimismo, el autor también explica que las condiciones económicas recrudecidas por las políticas neoliberales de los 90 produjeron una "cultura del reviente" que reemplazó ese tradicional "aguante", por ejemplo en el abuso de drogas en barrios populares.

19 Para ampliar sobre la perspectiva de género en el deporte ver Scharagrodsky (2004).

20 Conurbano por la Diversidad es una organización territorial integrada por disidentes sexuales de las periferias bonaerenses que busca exaltar estas particularidades omitidas en el discurso de un tipo de estilo de vida "gay" que se posiciona como hegemónico en tanto término europeizado y lavado por el ethos capitalista.

21 Fuente: http://www.infonews.com, 23/04/18.

22 Entre las funciones que hacen de Bahía Blanca el principal centro de la región del sudoeste de la provincia de Buenos Aires están las educativas. Posee dos universidades (la otra es la Universidad Tecnológica Nacional), siendo la Universidad Nacional del Sur la que ostenta un fuerte reconocimiento social de acuerdo a las representaciones de sus ciudadanos.

23 Reclamos de vecinos contra las edificaciones en altura que deterioraban algunas prestaciones de servicio por su alta demanda (principalmente la escasez de agua durante el verano) llevó al municipio a labrar una nueva norma para el barrio (delimitado por Estomba y avenida Alem, entre Perú y el Canal Maldonado), la cual dejó de permitir la construcción de edificios en altura (la 16.124 anterior permitía hasta tres pisos) y destinó la aprobación únicamente a viviendas en planta baja, respetando así el pedido de los vecinos para que no se modifique el perfil histórico del barrio.

24 Así se denomina uno de los espacios pertenecientes al Club Universitario de Bahía Blanca contiguo a las instalaciones de la universidad, orientado principalmente al divertimento nocturno, cuyos principales demandantes han sido los estudiantes de esta casa de estudios.

25 En este punto se recomienda la lectura de Delgado Ruiz (2007), Sociedades Movedizas. 